\title{
CARACTERIZACIÓN HISTOLÓGICAY DINÁMICA LINFOIDE DE LAS PLACAS DE PEYER EN CRÍAS DE ALPACA DURANTE LOS 45 PRIMEROS DÍAS DE VIDA
}

\author{
Histological Characterization and Lymphoid Dynamics of Peyer's Patches \\ in the First 45 Days of Age of Alpacas
}

Víctor Roca L. ${ }^{1}$, Alberto Manchego S..,3, Nieves Sandoval C. ${ }^{2}$, Kim Lam Chiok C. ${ }^{1}$, Hermelinda Rivera G. ${ }^{1}$

\section{Resumen}

\begin{abstract}
El objetivo del estudio fue describir las características histológicas de las placas de Peyer (PP) en yeyuno e íleon en 33 crías de alpaca de 0 a 45 días de edad. Se colectaron las porciones del yeyuno e íleon y las muestras se fijaron en formaldehído al $10 \%$ tamponado. Se obtuvieron láminas histológicas coloreadas con Hematoxilina-Eosina y láminas positivadas con poli-L-lisina con muestras de yeyuno e íleon para detección de linfocitos T por inmunohistoquímica, utilizando anticuerpos monoclonales contra CD-8 y el sistema de revelado Histostain. Histológicamente, las crías al nacimiento muestran organizaciones linfoides asociadas a mucosa intestinal bien definidas tanto en yeyuno e íleon. En crías mayores de 14 días se observa un mayor crecimiento conformado por las placas de Peyer yeyunales (PPY), que presentan una región de linfocitos activos y otra de células no diferenciadas. Se encontró gran actividad y positividad al marcador CD8 en los linfocitos agrupados en folículos y PP, tanto yeyunales como del íleon (PPI) a partir de crías de 6-10 días. El número de linfocitos que expresan CD8 se incrementa a medida que aumenta la edad del animal. Se concluye que existe un desarrollo de las PPI y PPY anterior al nacimiento, siendo las PPI las que sufren una involución y las PPY las que persisten durante toda la vida del animal, siendo ambas activas posnacimiento.
\end{abstract}

Palabras clave: alpaca, CD8, inmunohistoquímica, linfocitos, placas de Peyer

\footnotetext{
${ }^{1}$ Laboratorio de Microbiología y Parasitología Veterinaria, ${ }^{2}$ Laboratorio de Histología, Embriología y Patología Veterinaria, Facultad de Medicina Veterinaria, Universidad Nacional Mayor de San Marcos, Lima

${ }^{3}$ E-mail: amanchegos@gmail.com
}

Recibido: 30 de octubre de 2012

Aceptado para publicación: 15 de marzo de 2014 
The study aimed to describe the histological features of Peyer's patches in jejunum and ileum of 33 newborn alpacas from 0 to 45 days of age. Sections of jejunum and ileum were collected and fixed in $10 \%$ buffered formaldehyde. Standard histological slides stained with hematoxylin-eosin were obtained and poly-L-lysine coated slides were used for detection of $\mathrm{T}$ cells by immunohistochemistry using monoclonal antibodies against CD-8 marker aided by Histostain development system. Histologically, newborn alpacas showed organized and well defined intestinal mucosa-associated lymphoid tissue in both, jejunum and ileum. In animals older than 14 days of age, jejunal Peyer's patches develop showing regions of active cells and other areas of undifferentiated lymphoid cells. It was also found a very active and positive reaction to CD8 marker on lymphocytes grouped in follicles and on Peyer's patches of jejunum and ileum of animals from 6 to 10 days of age and onwards. The number of CD8 (+) lymphocytes increases according to the animal's age. It is concluded that Peyer's patches develop before birth in the ileum and jejunum, both locations being active after birth although ileal Peyer's patches decrease in time while jejunal Peyer's patches persist through lifespan.

Key words: alpaca, CD8, inmunochemistry, lymphocytes, Peyer's patches

\section{INTRODUCCIÓN}

La crianza de camélidos sudamericanos en el Perú es una de las actividades pecuarias más importantes para la población económicamente activa de la Sierra. Una de las limitantes de su desarrollo son los problemas sanitarios, siendo las infecciones de tipo entéricas, sobre todo la colibacilosis (E. coli) y la enterotoxemia (Clostridium perfringens) las principales afecciones, a pesar que estas bacterias son susceptibles a tratamientos con antibióticos (Pezo et al., 1998).

El sistema inmune asociado al tracto digestivo de los rumiantes se encuentra formado por células linfoides presentes en tejidos linfoides organizados principalmente en placas de Peyer, y en menor proporción, en toda la lámina interna del intestino como células intraepiteliales (Tizard, 2002). Los rumiantes tienen dos tipos de placas de Peyer, las del íleon (PPI) y las yeyunales (PPY), las cuales difieren en su desarrollo, composición celular y función (Landsverk et al., 1991). Las placas están formadas por linfocitos $\mathrm{T}$, linfocitos B, macrófagos y otras células pre- sentadoras de antígenos, como las células dendríticas (Tizard, 2002). Los folículos linfoides asociados a mucosas son los que entran en contacto inmediato con los microorganismos de la flora normal bacteriana y también con la patógena (Aleksandersen et al., 2002).

Se ha determinado que los antígenos de la flora normal estimulan el desarrollo de estos tejidos linfoides y que estimulan la respuesta inmune de mucosas contra los patógenos (Gulberg y Soderholm, 2006); sin embargo, muchos enteropatógenos utilizan a estas placas para poder internalizarse a otros órganos blanco y, además, algunas exotoxinas bacterianas pueden inhibir la proliferación de tejido linfoide (Sanz, 2001). En el presente trabajo se hace una descripción histológica de la organización de las células linfoides en las placas de Peyer del íleon y del yeyuno en crías de alpaca.

\section{Materiales y Métodos}

Se utilizaron 33 muestras de alpacas aparentemente sanas, de 0 a 45 días de edad, 
que fueron sacrificadas en el camal municipal. Se trabajaron cortes transversales y longitudinales de $4 \mathrm{~cm}$ de las porciones medias del yeyuno e íleon. Cada muestra fue dividida en dos porciones de $2 \mathrm{~cm}$, donde la primera porción se utilizó para el estudio histológico, embebida en formaldehido tamponado al $10 \%$, y la segunda porción, almacenada en nitrógeno líquido $\left(-196^{\circ} \mathrm{C}\right)$, para el estudio inmunohistoquímico. Las muestras se estratificaron en tres grupos etarios: GE1, 13 animales de 0 a 14 días; GE2, 6 animales de 15 a 30 días; y GE3, 14 animales mayores de 30 días.

Las muestras formolizadas se procesaron según protocolos estándares para estudios histológicos con la tinción HematoxilinaEosina. Se empleó un microscopio binocular (ocular 10x y objetivos de 10, 40 y 100x, Carl Zeiss Primo Star, Alemania) y las fotografías fueron tomadas con cámara digital (Canon Power Shot G, 12.1 megapixels, Japón).

Se hicieron cortes de $4 \mu \mathrm{m}$ en el tejido congelado $\left(-196{ }^{\circ} \mathrm{C}\right)$ de yeyuno e íleon con un criostato Leica Jung CM 1800. Las muestras congeladas fueron fijadas con acetona fría por 10 min en láminas portaobjeto tratadas con Poly-L-Lisina (Sigma, EEUU), y luego procesadas según el protocolo de inmunohistoquímica del kit Invitrogen Histostain ${ }^{\circledR}$, utilizando el anticuerpo monoclonal anti-CD8 (LT5A $1 \mathrm{mg} / \mathrm{ml} \mathrm{del}$ Laboratorio VRMD en solución de trabajo 1:20). El patrón utilizado para la identificación y recuento de folículos linfoides en una placa de Peyer a nivel microscópico se hizo de acuerdo a Sánchez-Vizcaíno (2004) y Scauri (2008). Se consideró todo el corte histológico ( $2 \mathrm{~cm}$ de largo) de la lámina, tanto en yeyuno como el íleon. Los animales se estratificaron en tres grupos etarios y se promedió el número de folículos linfoides contabilizados en los cortes histológicos teñidos con HE. Las escalas fueron establecidas en tres grupos:
- Grupo 1: Muestras con 1 a 2 folículos linfoides en promedio por campo. Corresponden a muestras con poco tejido linfoide organizado $(+)$.

- Grupo 2: Muestras con 3 a 6 folículos linfoides en promedio por campo (++).

- Grupo 3: Muestras con 7 o más folículos linfoides en promedio por campo. Corresponden a muestras con gran cantidad de tejido linfoide organizado (+++).

En la determinación del número de linfocitos en los folículos linfoides, dada la dificultad de realizar un contaje individual, se establecieron dos grupos: alta densidad (AD), determinada como alto acúmulo o agregado de linfocitos en un campo óptico, y baja densidad (BD), como un bajo acúmulo (disperso) de linfocitos en un campo óptico.

Se utilizó el programa Axio Vision Rel 4.7 para medir los folículos linfoides en la placa de Peyer (ancho, largo y área en micras) de las láminas tratadas con inmunohistoquímica. Los linfocitos positivos al marcador monoclonal CD8 se visualizan de color pardo y fueron enumerados dentro del agregado linfoide con un contador manual (Leica, Suiza).

\section{Resultados}

Desde el nacimiento (Día 0), tanto en yeyuno como en íleon se observa organizaciones linfoides asociadas a mucosa intestinal (GALT, por sus siglas en inglés) bien definidas como las Placas de Peyer y folículos linfoides pequeños (Fig. 1) en baja densidad (BD) (Fig. 2), así como linfocitos intraepiteliales en la submucosa.

En el grupo GE1 (0-14 días), los folículos linfoides de las placas de Peyer del yeyuno son más pequeños que los del íleon (Cuadros 1 y 2); sin embargo, esta relación disminuye drásticamente con la edad. A partir del día 1 de edad, es posible observar las partes del folículo como son la corona, región 


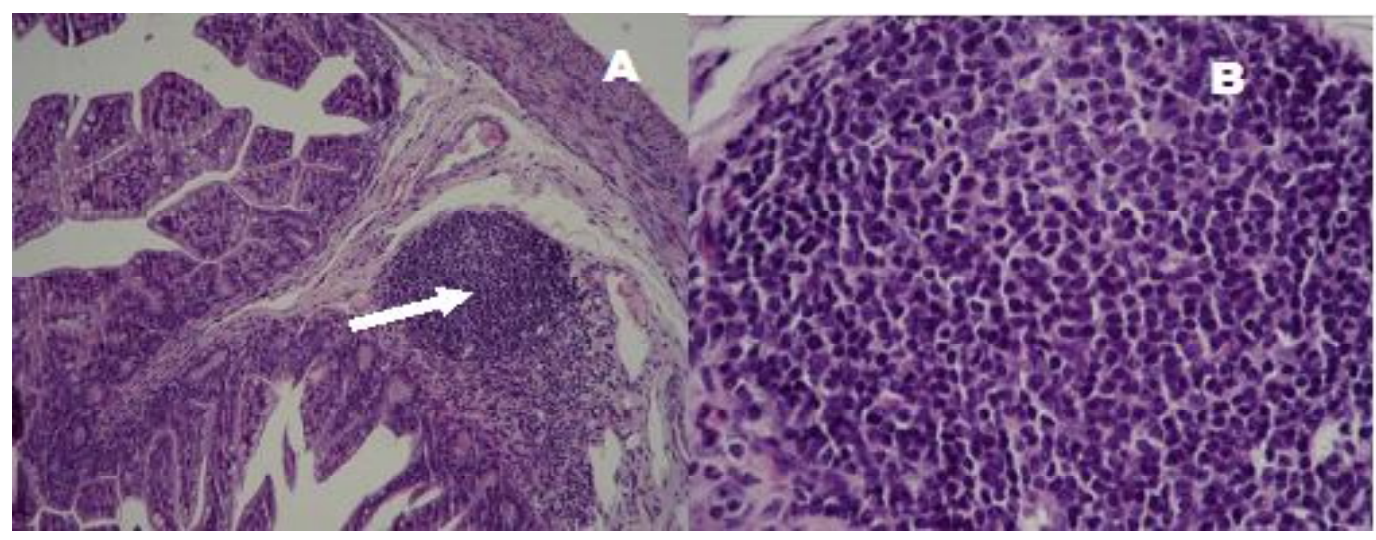

Figura 1. Yeyuno de alpaca recién nacida (0 días). Presencia de folículo linfoide en la submucosa (A) Distribución uniforme sin centros germinales definidos (100x); (B) El área señalada por la flecha en A en mayor aumento (400x)

interfolicular y la cúpula (la cual es muy difícil de distinguir histológicamente), tanto en yeyuno como en íleon (Fig. 3). Los folículos linfoides de la placa de Peyer del íleon abarcan una gran extensión de la submucosa, formando áreas linfoides con baja densidad celular y distribuida uniformemente (Fig. 4A).

En el grupo GE2 (15 a 30 días) se observa un crecimiento más marcado de folículos linfoides en las placas de Peyer presentando una región de linfocitos activos. Existe un mayor crecimiento de las placas de
Peyer yeyunales de manera gradual desde el nacimiento hasta los 45 días. En GE1, las placas ileales presentan un crecimiento estacional del tejido linfoide que se focaliza y restringe a la submucosa, haciéndose más evidente a partir de los siete días. En los grupos GE2 y GE3, los folículos linfoides que conforman las placas de Peyer son más escasos y aumenta el espacio interfolicular (Cuadro 3); asimismo, se puede diferenciar centros de germinación de linfocitos en todo el recorrido del tejido (Fig. 4).
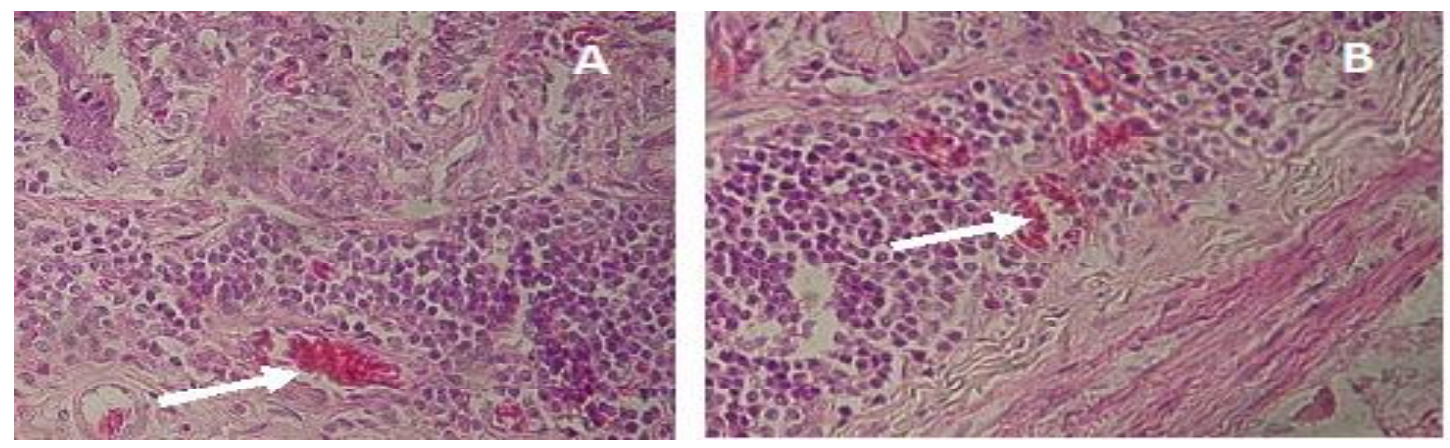

Figura 2. Íleon de alpaca recién nacida (0 días). (A y B) Presencia de tejido linfoide en submucosa con baja densidad celular linfoide (BD). HE, 400x 


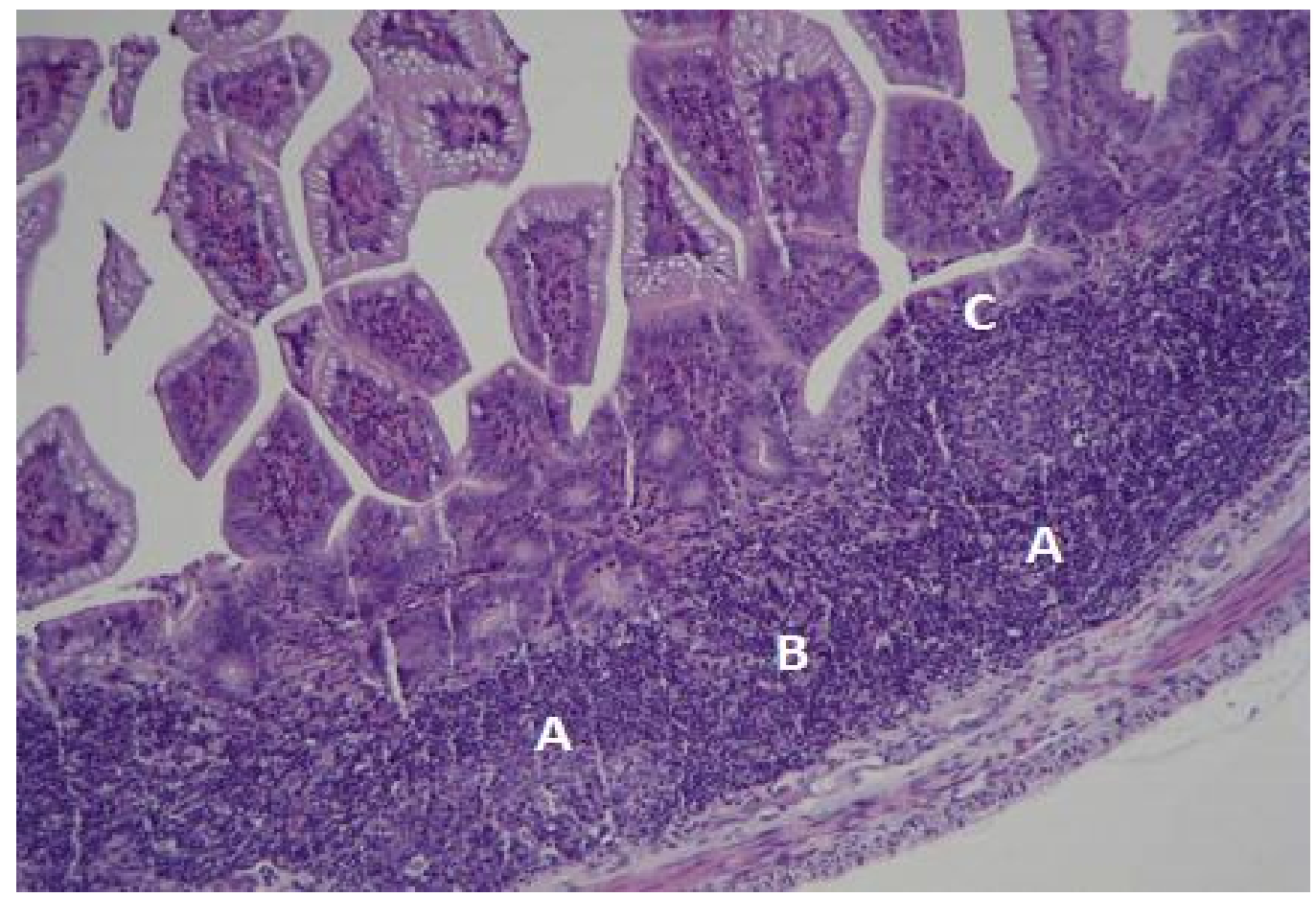

Figura 3. Íleon de alpaca de un día de edad. Placa de Peyer con regiones histológicas definidas: Centros germinales (A) en los folículos linfoides, región interfolicular (B) y la corona (C). HE (100x)

La morfometría de las placas de Peyer del yeyuno muestra en la primera semana (67 días) un incremento en el área que ocupa, junto con un incremento del número promedio de folículos linfoides, determinando áreas de alta densidad linfoide (Cuadro 1).

En la morfometría de las placas de Peyer del íleon, el número de folículos linfoides disminuye; sin embargo, el área promedio de la PP se incrementa hasta la segunda semana (14 días de edad), (Cuadro 2).

Ninguna muestra presentó una cruz en el G1, mientras que el $61.5 \%$ de las muestras presentaron dos cruces para presencia de folículos linfoides en una placa de Peyer (Cuadro 3), lo cual indica que tuvieron entre 3 a 6 folículos linfoides en una placa de Peyer por área de observación. Entre los animales de G2, el $66.7 \%$ presentó una cruz y el resto presentó dos cruces. En el grupo G3, el 64.3\% presentó una cruz.

La inmunohistoquímica indica la presencia de la proteína CD8 en los linfocitos agrupados en folículos aislados y en las placas de Peyer, tanto yeyunales como del íleon en animales de 6 a 10 días, respectivamente (Fig. 5).

\section{Discusión}

El estudio determinó que las crías de alpaca muestran un tejido linfoide bien definido, asociado a la mucosa desde el nacimiento y similar a lo encontrado en otros rumiantes (Parsons et al., 1989). Desde el primer día de edad, tanto en yeyuno como en íleon, se observan folículos linfoides, mostrando una 


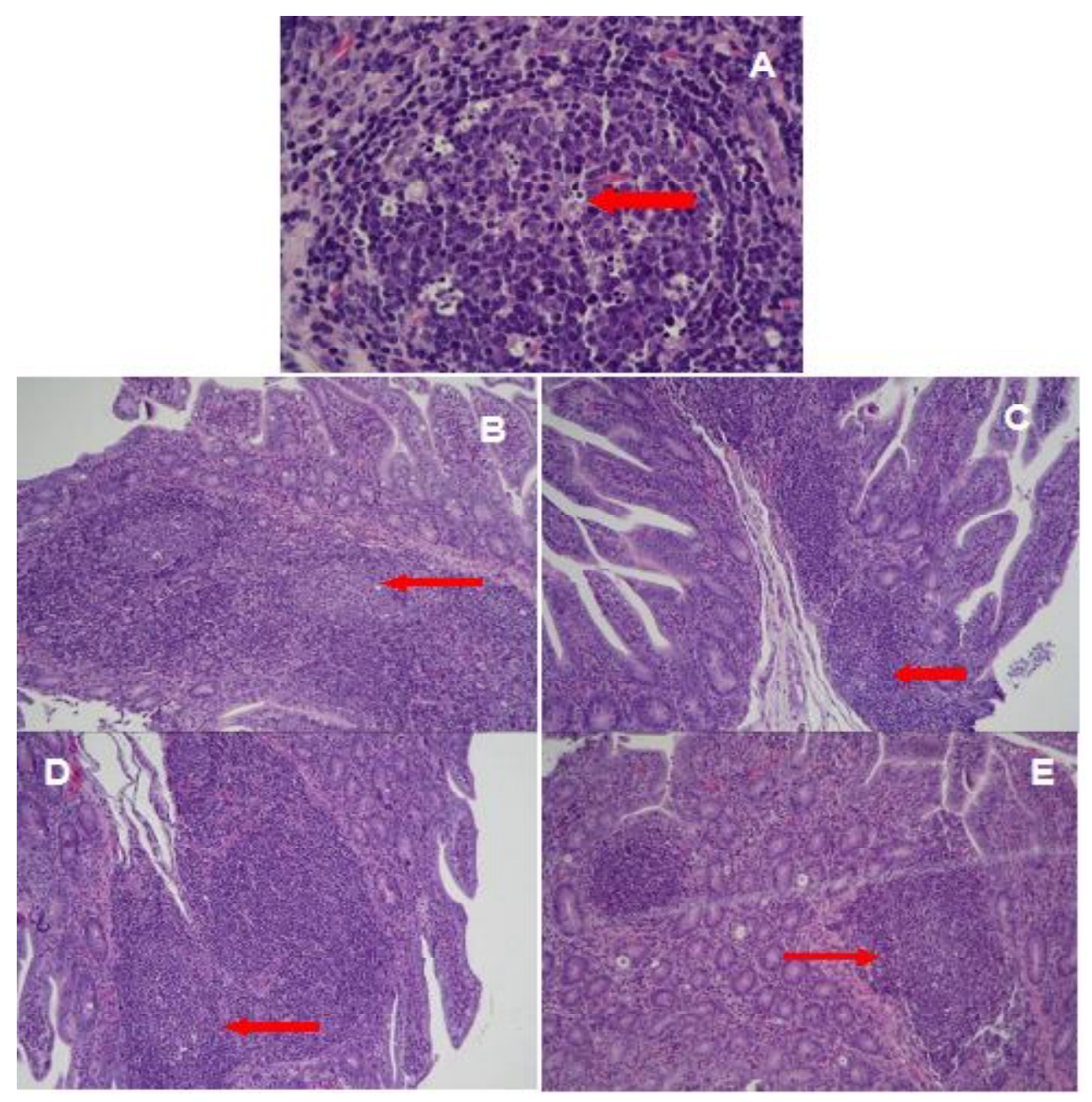

Figura 4. Íleon de crías de alpaca. Crecimiento de folículos linfoides de placas de Peyer a distintas edades: 1 día (A) (400x), 4 días (B), 7 días (C), 18 días (D), 30 días (E). Las flechas indican el centro de germinación de linfocitos. HE (100x)
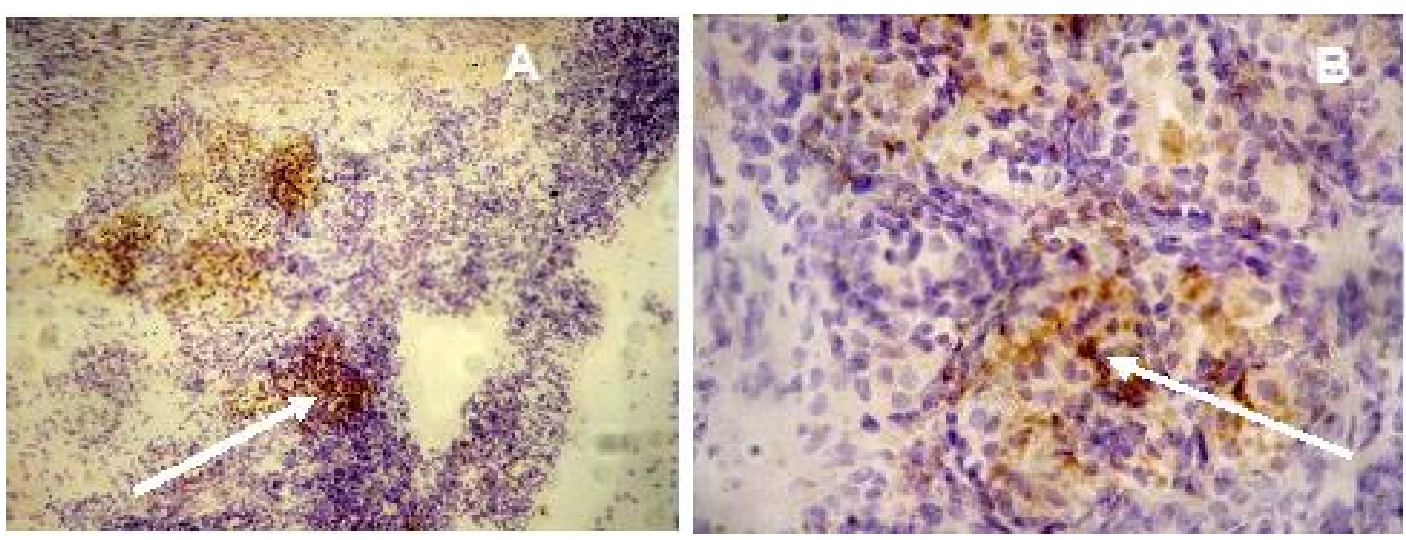

Figura 5. Íleon de alpaca de seis días. Inmunohistoquímica (IHQ) con anti-CD8 de bovino en tejidos congelados. Se aprecia los linfocitos marcados positivos (flechas). A: 100x; B: 400x 
Cuadro 1. Número de folículos linfoides en placas de Peyer, linfocitos CD8+ y densidad linfoide en yeyuno de las crías de alpacas (100x)

\begin{tabular}{cccccc}
\hline $\begin{array}{c}\text { Folículos linfoides } \\
\text { (HE) }\end{array}$ & \multicolumn{4}{c}{ Morfometría promedio de folículos linfoides y presencia de } \\
linfocitos CD 8+ \\
\hline $\begin{array}{c}\text { Edad } \\
\text { (días) }\end{array}$ & Número & $\begin{array}{c}\text { Área } \\
\left(\mu \mathrm{m}^{2}\right)\end{array}$ & $\begin{array}{c}\text { Linfocitos } \\
\text { CD8+ }\end{array}$ & $\mathrm{AD}^{1}$ & $\mathrm{BD}^{1}$ \\
\hline 0 & 3 & 26164 & 0 & & $\mathrm{X}$ \\
1 & 3 & 2696 & 0 & $\mathrm{X}$ & \\
6 & 6 & Linfocitos difusos & 82 & $\mathrm{X}$ & \\
7 & 5 & Linfocitos difusos & 33 & $\mathrm{X}$ & \\
11 & 3 & Linfocitos difusos & 201 & $\mathrm{X}$ & \\
17 & 5 & 24420 & 0 & & $\mathrm{X}$ \\
18 & 5 & 23411 & 16 & $\mathrm{X}$ & \\
\hline
\end{tabular}

${ }_{2}^{1}$ AD: Alta densidad; BD: Baja densidad

${ }^{2}$ Los linfocitos difusos se encuentran en todo el campo visual, no solo limitándose a la submucosa sino infiltrándose tanto en la mucosa y en la lámina propia (también linfocitos intraepiteliales). Esto es compatible con una hiperplasia linfoide

Cuadro 2. Número de folículos linfoides en placas de Peyer, linfocitos CD8+y densidad linfoide en íleon de las crías de alpacas (100x)

\begin{tabular}{|c|c|c|c|c|c|}
\hline \multicolumn{2}{|c|}{$\begin{array}{l}\text { Folículos linfoides } \\
\qquad(\mathrm{HE})\end{array}$} & \multicolumn{4}{|c|}{$\begin{array}{l}\text { Morfometría prome dio de los folículos linfoides y linfocitos } \\
\qquad \text { CD } 8+\end{array}$} \\
\hline Edad (días) & Número & $\begin{array}{l}\text { Área } \\
\left(\mu \mathrm{m}^{2}\right)\end{array}$ & $\begin{array}{c}\text { Linfocitos } \\
\text { CD8+ }\end{array}$ & $\mathrm{AD}^{1}$ & $\mathrm{BD}^{1}$ \\
\hline 0 & 6 & 7149 & 0 & & $\bar{X}$ \\
\hline 1 & 3 & 11874 & 0 & $\mathrm{X}$ & \\
\hline 6 & 3 & 191741 & 0 & $\mathrm{X}$ & \\
\hline 7 & 3 & 187464 & 0 & $\mathrm{X}$ & \\
\hline 10 & 3 & Linfocitos difusos & 83 & $\mathrm{X}$ & \\
\hline
\end{tabular}

mayor densidad celular en la parte externa del folículo (corteza) y menos densa en la parte central (médula), lo cual es característica de un folículo linfoide que desde las pri- meras horas de vida tiene contacto con múltiples antígenos (Cesta, 2006), provenientes principalmente de bacterias presentes en su medio ambiente. 
Cuadro 3. Distribución de animales en relación con la cantidad de folículos linfoides observados en placas de Peyer (yeyuno e íleon) en $2 \mathrm{~cm}$ de extensión de corte histológico, según estrato etario

\begin{tabular}{|c|c|c|c|c|}
\hline \multirow{2}{*}{$\begin{array}{c}\text { Grupo etario, } \\
\text { días }\end{array}$} & \multicolumn{4}{|c|}{ Número de folículos linfoides ${ }^{1}$} \\
\hline & + & ++ & +++ & Total \\
\hline $0-14 \quad(\mathrm{G} 1)$ & 0 & 8 & 5 & 13 \\
\hline $15-30 \quad(\mathrm{G} 2)$ & 4 & 2 & 0 & 6 \\
\hline$>30 \quad(\mathrm{G} 3)$ & 9 & 4 & 1 & 14 \\
\hline Total & 13 & 14 & 6 & 33 \\
\hline
\end{tabular}

${ }^{1}+=1$ a $2 ;++=3$ a $6 ;+++=7$ o más

Los hallazgos demuestran que, en los primeros días de edad, los folículos de las placas de Peyer yeyunales (PPY) se encuentran en menor número que los del íleon (PPI). Estos últimos ocupan la mayor parte de la submucosa y sufren una involución de manera similar (a partir de los 18 días aproximadamente) a lo que sucede en el timo de los mamíferos domésticos.

Todo lo contrario sucede con los folículos linfoides de las placas de Peyer yeyunales, los cuales están en bajo número al nacimiento y se incrementan a partir de los 18 días, para persistir durante toda la vida del animal. La presencia temprana de PPY se puede deber a que el calostro y la leche contienen elementos moduladores del sistema inmune de mucosas; así, la prolactina presente en el calostro y la leche materna inducen rutas de señalización celular a través de su receptor para la proliferación celular (Ellis et al., 1997).

La técnica de inmunohistoquímica, utilizando el anticuerpo monoclonal contra la proteína CD8 que identifica a los linfocitos $\mathrm{T}$ citotóxicos, permite demostrar que este tipo de linfocitos está ampliamente distribuido en el tejido linfoide asociado a mucosa intestinal. Se les detectó en los folículos linfoides de las placas de Peyer, pero en mayor canti- dad en la submucosa como linfocitos intraepiteliales de manera similar a lo encontrado por Zaldívar (2002) en otros animales domésticos.

La reacción positiva usando anticuerpos anti-CD8 de bovino implica que existe una reacción cruzada con el CD8 de alpaca, detectando un epítopo común. El marcador utilizado (CD8) presenta una actividad y positividad tanto en folículos linfoides yeyunales e ileales en animales de 6 y 10 días, respectivamente, debido a que cambia la proporción de linfocitos activos y no activos. Los animales menores de 6 días son los que presentan una mayor reacción positiva a nivel de linfocitos intraepiteliales en yeyuno. En el caso de íleon, los animales menores de 10 días presentan reacción idéntica. Esto se debería a que en un primer momento quien asume la función de inmunidad de mucosas en el intestino son los linfocitos intraepiteliales.

\section{Conclusiones}

- El tejido linfoide asociado a mucosa intestinal está estructuralmente completo al nacimiento de la cría de alpaca, pero es funcional con los primeros contactos con los antígenos de la flora microbiana del intestino. 
- El anticuerpo anti-CD 8 de bovino identifica a su homólogo en las células linfoides de alpaca y permitió observar la presencia de los linfocitos TCD8+ en la mucosa intestinal del yeyuno e íleon a los 6 y 10 días, respectivamente.

\section{Agradecimientos}

El trabajo se realizó con financiamiento del Proyecto 065-FINCyT-PIBAP-2008. Los autores agradecen a los MV Juan More y Mercy Ramírez y al técnico Vicente Mercado por el apoyo brindado y a la MV María Vásquez por su apoyo en la redacción del documento.

\section{Literatura CitTada}

1. Aleksandersen M, Lie K.L, Gjerbe B, Landsverk T. 2002. Lymphocyte depletion in ileal Peyer's patch follicles in lambs infected with eimeria ovinoidalis. Clin Diagn Lab Immunol 9: 83-91.

2. Cesta MF. 2006. Normal structure, function, and histology of mucosaassociated lymphoid tissue. Toxicol Pathol 34: 599-608.

3. Ellis LA, Mastro AM, Picciano MF. 1997. Do milk-borne cytokines and hormones influence neonatal immune cell function? J Nutr 127: 985S-988S.

4. Gulberg E, Soderholm J. 2006. Peyer's patches and M cells as potential sites of the inflammatory onset in Crohn's disease. Ann N YAcad Sci 1072: 218-232.
5. Landsverk $T$, Halleraker $M$, Aleksandersen M, McClure S, Hein W, Nicander L. 1991. The intestinal habitat for organized lymphoid tissues in ruminants: comparative aspects of structure, function and development. Vet Immunol Immunopathol 28: 1-16.

6. Parsons KR, Howard CJ, Jones BV, Soop P. 1989. Investigation of bovine gut associated lymphoid tissue (GALT) using monoclonal antibodies against bovine lymphocytes. Vet Pathol 26: 396-408.

7. Pezo D, García W, Franco E. 1998. Ensayo del control de la enteritis neonatal en crías de alpaca y llamas. En: Proc XXI Reunión Científica Anual Asociación Peruana de Producción Animal. Puno, Perú: APPA. p 248-249.

8. Sanz M. 2001. Inmunidad y prevención de la alergia a alimentos. Alergol Inmunol Clin 16(2): 58-75.

9. Scauri A. 2008. Íleo - Placas de Peyer (GALT). [Internet]. Disponible en: www.flickr.com/photos/andrea_scauri/ 3057337330/

10. Sánchez-Vizcaíno J. 2004. Curso de Introducción a la inmunología porcina. $2^{\mathrm{a}}$ ed.[Internet]. Disponible en: www. sanidadanimal.info/curso/inmuno2/

11. Tizard I. 2002. Inmunología veterinaria. $3^{a}$ ed. México: Interamericana McGraw- Hill. 414 p.

12. Zaldívar M. 2002. El sistema inmunológico de las mucosas. Rev Cubana Med Gen Integr 18(5): 352-354. [Internet] Disponible en: http://scielo.sld.cu/ scielo.php?script=sci_arttext\&pid=S086421252002000500012\&lng=es 